\title{
Police Interactions with the Mentally Ill: The Role of Procedural Justice
}

\section{Farzana B. Kara}

Simon Fraser University School of Criminology

Police encounters with mentally ill individuals that involve the use of force by police are relatively infrequent, but sometimes quite volatile. This article discusses the use of procedural justice theory in understanding the quality and consequences of such interactions. Procedural justice theory and its specific application to the police who interact with mentally ill persons are discussed as a promising approach in improving police-citizen interactions. This paper provides an empirical basis for understanding the need for evidence-based police policy and practices when dealing with the mentally ill.

Keywords: police encounters; mentally ill persons; use of force; procedural justice.

Il est assez rare que les rencontres entre les agents de police et les personnes souffrant de maladies mentales donnent lieu à des démonstrations de force par les policiers, mais ces rencontres peuvent être volatiles. La désinstitutionalisation des personnes souffrant de maladies mentales, des services alternatifs peu financés et fragmentés dans la collectivité et les critères de plus en plus restrictifs d'engagement civil ont contribué à l'augmentation des contacts avec les forces policières. Les agents de polices doivent faire preuve de retenue dans la force employée contre les personnes souffrant de maladies mentales. Les besoins sont clairs de former les policiers à une intervention spécialisée auprès des personnes souffrant de maladie mentale. La théorie de la justice procédurale propose une méthode prometteuse pour améliorer les relations de la police avec les citoyens. Selon ce cadre, le traitement équitable d'un individu par un agent d'autorité come un policier peut influer sur la perception de la légitimité de son intervention, et de toutes les impressions qui y sont associées, ce qui est d'une importance particulière pour les interactions entre les policiers et les personnes souffrant de maladie mentale.

Mots clés: rencontres de police; les personnes souffrant de troubles mentaux; l'utilisation de la force; la justice procédurale.

\section{Introduction}

\section{The Police and the Mentally Ill}

Several explanations have been advanced from different perspectives to clarify the reasons for the increasing numbers of contacts between the police and people living with mental illness. Three major developments are often speculated to have contributed to this increase (Teplin, 1984a). The policy of deinstitutionalization from mental health facilities that has been implemented over the past four decades is a central factor that has led to an influx of mentally ill people living in the community (Lamb et al., 2002), thereby increasing the likelihood of police-mentally disordered people encounters. In addition, overly restrictive civil commitment criteria and poorly funded and fragmented community-based mental health services are all interrelated factors that have led to frequent encounters between the police and the mentally ill. 


\section{Deinstitutionalization}

The treatment of mental illness has undergone a significant transformation over time, from institutionalized care in psychiatric hospitals to community-based treatment (U.S. Department of Justice, 1993). For most of the twentieth century, the treatment of people with serious mental illness was addressed through institutions like hospitals and asylums (Cook \& Wright, 1995). Long-term confinement in strictly controlled environments, much like prisons, was the norm. In his seminal work on "total institutions", Goffman (1961) proffered an analysis of asylums where he described the role of the institution in forming the patient's self-identity and the patient's adjustment to life inside the mental hospital. His analysis is built on the social structure and social consequences of institutionalization, not the mental illness itself. Other sociological works were also influential in highlighting the relationship between social class, urban life and mental illness and the implications of labeling people living with mental illness (Cook \& Wright, 1995). The long-term care of psychiatric patients in such institutions clearly had harmful consequences including the loss of liberty, forced dependency, and acceptance of a regimented existence. However, the lack of effective psychotropic medications precluded managing this population in any other way.

During the 1930s, psychologists began to argue against institutionalization of the mentally ill, and instead argued for community-based mental health services (Commission for Public Complaints Against the RCMP, 2010a). Advocates of community-based intervention argued that the practice of "warehousing" mental patients in asylums was inhumane and not conducive to treatment (Commission for Public Complaints Against the RCMP, 2010a). Further, by the mid 1950 s, the rising costs of mental institutions were creating increasing financial burdens on governments who were looking for cost-saving alternatives. In addition, with the advent of new psychotropic medications such as Ziprasidone, Asenapine and Aripiprazole for severe mental illnesses, patients could be properly treated for their illness while living on their own in the community (Cook \& Wright, 1995).

The social, economic and political conditions during the mid-1900s, discussed above, all created an environment that called for the deinstitutionalization of the mentally ill. Consequently, beginning in the 1960s, there was a worldwide trend towards moving psychiatric patients from mental hospital settings to less restricting settings in the community (Sealy \& Whitehead, 2004). This resulted in drastic downsizing of institutions by eliminating hundreds of psychiatric beds which were previously meant for mentally ill people (Smyth, 2006). This shift towards communitybased treatment was an approach to mental health that is geared towards the hope of recovery rather than incapacitation.

While deinstitutionalization was theoretically beneficial in keeping the mentally ill out of institutions where they were treated with little or no human dignity, in practice, the process was an abject failure. As institutions began downsizing, hundreds of vulnerable people were displaced to socially disorganized neighbourhoods such as Vancouver's notorious Downtown Eastside. Displacement resulted from the improper implementation of post-deinstitutionalization policies. A lack of community residential facilities and inadequate mechanisms to ensure the mentally ill adhered to a consistent treatment plan contributed to the failure of deinstitutionalization. Many of these people were left to "[claw] out a pitiable existence on [the] streets, in dumpsters, in filthy and dangerous skid-row hotels or in jails" (Smyth, 2006, p. b4). While there is nothing wrong with the policy of deinstitutionalization, this shift was not accompanied by the development of communitybased services, an alternative that was never fully implemented. Consequently, many critics argue that deinstitutionalization has led to large numbers of people, who would once have been inpatients, 
being incarcerated in jails and prisons or becoming homeless when outpatient services are not available (Lowman, Menzies \& Palys, 1987).

It is important to note that deinstitutionalization is not the only reason for increased police encounters with mentally disordered persons. "Non-Institutionalization" of mentally ill individuals has been a policy that has been implemented by making the criteria for civil commitment more restrictive. However, most important is the fact that hospitalizations in the psychiatry wards of general hospitals are now fairly brief, leading to a revolving-door phenomenon in which patients are released after short periods of involuntary commitment and come into more frequent contact with the police.

\section{Community-Based Mental Health Services}

The deinstitutionalization movement and its failures was accompanied by reductions in government spending on mental health services that significantly limited the quantity of treatment programs available in the community (Commission for Public Complaints Against the RCMP, 2010a). Poorly funded and fragmented community-based mental health and social services cannot provide adequate treatment or supervision for people living with mental illness. Consequently, their condition is likely to deteriorate as their behaviour becomes more difficult to manage. Coupled with homelessness and poverty, this vulnerable group is likely to find themselves on the streets, increasing their likelihood of coming into contact with police (Commission for Public Complaints Against the RCMP, 2010a).

\section{Civil Commitment}

The current civil commitment criteria reflect the contextual changes that have occurred over the past three decades. Involuntary or civil commitment historically, limited the rights of the individual in favour of social control by compelling non-consensual isolation and treatment (Hermann, 1986). However, during the 1960s and 1970s, this raised some concern among civil libertarians and social justice advocates regarding the fairness and constitutionality of such laws. As a result, many of the reforms that followed were concerned with civil liberties and patient's rights which produced more stringent criteria governing commitment and treatment (Teplin, 1984a). Thereafter, the legal system became the arbiter of the mental health system's decisions regarding treatment and hospitalization, particularly concerning involuntary treatment and hospitalization (Hiday, 2011).

Under the old civil commitment criteria, people suffering from any type of mood disorder or depression could often be civilly committed. However, with the restrictions that have since been adopted through new legal criteria, a number of jurisdictions now require a finding of "dangerousness" to self or others and requirements that treatment should be administered in the least restrictive institutional setting as prerequisites to involuntary civil commitment (Hermann, 1986). The reform of the dangerousness standard in civil commitment law has led to frequent arrests of mentally ill persons by police (Hiday, 1992). In all other cases, the least restrictive/intrusive intervention options should be applied. This may result in police encounters with mentally disordered people who are acting out, but cannot be brought into custody under the law. The restrictions on the powers of the police to detain and convey individuals into psychiatric care have necessitated frequent police interactions without long lasting solutions. The result is that larger numbers of people with mental disorders are living in the community without effective treatment (Teplin, 1984a), which increases the likelihood of mental health services (Verdun- 
Jones \& MacAlister, 2006). Under mental health legislation, most that their condition will become worse and their chances of encountering the police increase.

\section{Mental Health Law}

In Canada, each province and territory has legislation dealing with the provision provinces/territories have enacted at least two pieces of legislation: one which deals with the detention and treatment of mentally ill persons, and the other deals with issues surrounding the management of estates or personal life (Verdun-Jones \& MacAlister, 2006).

Most mental health acts set out the parameters of police involvement with the mentally ill (Teplin, 1984b). The current B.C. Mental Health Act affords the police with the power to place mentally ill individuals into police custody, and requires them to transfer the individual to a psychiatric hospital or mental health facility (Commission for Public Complaints Against the RCMP, 2008). Under the terms of the Act:

28 (1) A police officer or constable may apprehend and immediately take a person to a physician for examination if satisfied from personal observations, or information received, that the person

(a) is acting in a manner likely to endanger that person's own safety or the safety of others, and

(b) is apparently a person with a mental disorder.

(2) A person apprehended under subsection (1) must be released if a physician does not complete a medical certificate in accordance with section 22 (3) and (4)...

\section{Mental Health Act Changes}

In B.C., the current Mental Health Act has essentially remained unchanged since 1964. In the years since then, only minor revisions have been made to the act. While the overall differences in the commitment criteria between the pre-1964 legislation and the new act are not dramatic, some of the differences are noteworthy. Under the old Mental Hospitals Act, the involuntary commitment of individuals applied to persons who were certified to be "mentally ill" and requiring "care and maintenance in a mental hospital" (s. 11). The term "mentally ill person" was defined in s. 2 as:

a person who is suffering from such a disorder of the mind as to require care, supervision, and control of his own protection or welfare or for the protection of others, and includes any person of unsound mind also any person who is a lunatic within the meaning of the Lunacy Act.

Under the current Mental Health Act, civil commitment is only available for those persons who are suffering from a "mental disorder" and who require "treatment in or through a designated facility", who require "care, supervision and control" in such a facility to prevent "substantial mental or physical deterioration" or for the "protection of the person or the protection of others", and who "cannot suitably be admitted as a voluntary patient" (s. 22). A "person with a mental disorder" is defined in s. 1 as: 
a person who has a disorder of the mind that requires treatment and seriously impairs the person's ability

(a) to react appropriately to the person's environment or

(b) to associate with others...

As a result of these changes, police in this province who seek to bring a mentally ill person into custody, with a view to having them conveyed to a hospital for treatment, are faced with the reality that a person cannot be involuntarily admitted except in the direst of circumstances. Detention to ensure a person's welfare will no longer provide sufficient grounds upon which to justify involuntary commitment.

\section{Legal Perspective}

"The official mandate of the police includes dealing with mentally ill persons" has long been established (Bittner, 1967, p. 278). Police have a legal obligation to respond to all calls for service concerning people who are suffering from any mental-health related issues (Commission for Public Complaints Against the RCMP, 2010b). Police involvement with mentally ill persons is grounded in two common law principles: the power and responsibility of police to protect the welfare and safety of the community and their parens patriae duty to protect disabled citizens such as those suffering from mental illness (Ceyssens, 1994; Lamb et al., 2002; Teplin, 1984b, Teplin, 2000).

Police officers are afforded considerable discretion when dealing with the mentally ill. While the law legitimizes the power of police to intervene in situations involving mentally ill persons, it cannot dictate the "appropriate" response (Bittner, 1967, Teplin, 2000). Therefore, it is ultimately left to the discretionary judgments of the police to determine the most appropriate disposition when dealing with mentally disordered individuals, which could include transferring them to a psychiatric hospital, arresting them or informally resolving the matter (Teplin, 2000; Commission for Public Complaints Against the RCMP, 2010a).

Police are often the first responders to situations involving mentally ill persons; thus, they are essentially responsible for deciding whether a person is processed through the mental health system or via the criminal justice system (Menzies, 1987; Lamb et al., 2002), each resulting in a very different outcome. In their role as "forensic gatekeepers" or "frontline mental health workers", the disposition police officers choose is crucial and could potentially lead to criminalization (Menzies, 1987; Teplin, 2000). While Lamb (2009) argues that the criminal justice system is inappropriate for dealing with the mentally ill, the police are not entirely at fault for choosing this route, given their lack of dispositional alternatives and specialized training. Consequently, this can result in the criminalization of the mentally ill by police in many cases.

\section{The Criminalization of Mental Illness}

The criminal justice process, managed by legal agents, tends to criminalize and over-police marginalized groups such as Aboriginal peoples, the poor and racial minorities. Often, multiple sites of oppressions exist simultaneously across race, class, and gender boundaries, which can increase the likelihood of police encounters. Sadly, mentally ill individuals are no exception, and are yet another example of a marginalized group that is highly criminalized. There is widespread concern over the inappropriate use of arrest by police to resolve encounters with the mentally ill, a phenomenon referred to as the "criminalization of the mentally ill" (Abramson, 1972; Teplin, 
1984a; Hiday, 1999). Many mentally ill people who were previously treated under the mental health system are now cycled through the criminal justice system instead (Teplin, 1984a), demonstrating a classic example of "net-widening". It is important to recognize that, while mentally ill persons often come into contact with police as an offender or suspect of alleged criminal behavior, there is also an increased risk of criminal victimization among persons suffering from mental illnesses, thereby increasing the likelihood of police encounters (Brink et al., 2011).

There are several social and systemic factors which may result in the mentally ill being criminalized; however, it is unclear whether this assertion can be empirically supported (Teplin, 1984a). Research in this area has yielded some mixed results. Teplin (1984b) examined police encounters with mentally ill persons paying particular attention to the decision-making rules underlying disposition options. She highlighted the relative frequency of each dispositional option available to police. Her results indicated that hospitalization and arrest were highly infrequent events, accounting for $0.5 \%$ and $16.5 \%$ of dispositions respectively. Interestingly, informal resolution was the most common disposition, being used in $71.8 \%$ of cases involving mentally disordered persons. Further, the study found that, while arrest was not a common disposition used in police encounters with the mentally ill, the arrest rate was higher in cases involving "suspects exhibiting signs of serious mental disorder than that for non-mentally ill suspects for similar types of incidents" (Teplin, 1984b, p. 165). Similarly, Hiday (1999) examined the empirical evidence of prevailing beliefs about the mentally ill and the criminal justice system, and suggests that criminalization of the mentally ill is a reality. She too found arrest and incarceration rates to be much higher for mentally ill persons than for the general population.

In her seminal work on the attitudes of Canadian police officers toward the mentally ill, Cotton (2004) found that police officers actually displayed a high degree of compassion towards people suffering from mental illness, and they exhibited a desire to provide them with the appropriate mental health services. Despite their compassion for people suffering from mental illness, this marginalized population still suffers a high rate of arrest by police. However, Cotton (2004) argues that while arrest may be more common among mentally-ill people than nonmentally-ill people, she suggests that this could be attributed to factors other than criminalization such as lack of dispositional options.

\section{Stigmatization and False Perceptions of Mental Illness}

Previous studies have estimated that approximately one in five (20\%) Canadian adults will experience mental illness during the course of their life (Public Health Agency, 2002), ranging from mild to more severe forms. The serious stigma and discrimination associated with mental illness continues to be a harsh reality for those living with mental illness, and presents a barrier to seeking help (Public Health Agency, 2002). Without proper treatment, social support and community acceptance, a mentally ill individual can become extremely isolated, leading to thoughts of death or suicide.

The stigmatization and false perceptions of the mentally ill held by many people stem from a myriad of reasons including a lack of understanding or knowledge about mental illness, lack of empathy, stereotypes of mentally ill people as violent, dangerous or psychotic, and the tendency to fear (xenophobia) and exclude ("other") those who appear to be different (Public Health Agency, 2002; Teplin, 2000). Further, Teplin (2000) argues that society's tolerance for mentally ill individuals living in the community seems to be limited, with citizens often turning to the police to deal with the mentally ill. The impact of this behaviour has far-reaching consequences for the 
mentally ill and the community such as increased surveillance of marginalized groups, involuntary civil commitment, or the use of incarceration. The Canadian Alliance for Mental Illness and Mental Health (CAMIMH) has identified educating the public and media about mental illness to combat any preconceived notions, stereotypes or fear as a necessary first step towards addressing this situation.

\section{Police Use of Force}

Police use of force involving the mentally ill is an issue that has caused serious concern in recent years. Several cases involving police use of force have resulted in trauma, injury and even death. However, as previously mentioned, police encounters with the mentally ill involving use of force are quite rare, but several high profile cases have elevated the importance of this issue.

Under s. 25 of the Criminal Code, police are granted the authority to use force including lethal force:

25. (1) Every one who is required or authorized by law to do anything in the administration or enforcement of the law...

(b) as a peace officer or public officer..

is, if he acts on reasonable grounds, justified in doing what he is required or authorized to do and is using as much force as is necessary for that purpose.

Subsection (1) "creates a legal justification for individuals, including police officers, to use as much force as is necessary in the administration and enforcement of the law provided their actions are required or authorized and they act on reasonable grounds" (MacAlister, 2010, p. 77). However, Blumberg (1993) notes that many changes in the statutes, administrative policies and policies pertaining to police use of force, have occurred. For instance, s. 25 of the Criminal Code has been supplemented by policy in various police agencies which affects police authority to use force. In B.C., these policies are created by each individual police department under the authority of the Police Act - Use of Force Regulation. In Vancouver, for example, police regulations authorize police officers to use force in order to forcibly take someone believed to be mentally ill to a hospital for treatment if they reasonably believe that person is incapable of making a rational decision about whether to accept or refuse medical treatment due to their mental condition (Regulations and Procedures Manual, c. 1.2.2).

While the police have been granted the authority to use force in carrying out their duties, they must be careful to ensure they only use a level of force that is reasonable in the circumstances. Verdun-Jones and MacAlister (2006) have shown that police will be liable in negligence for improper use of force in bringing a mentally disordered person into their custody, and even criminal culpability for assault may follow if they use excessive force in taking a person with a mental disability into their care under mental health legislation.

\section{Increased Police Training}

In contemporary society, police interactions with the mentally ill have become part of the nature of policing. Research has suggested a high number of calls for service involving mentally ill persons in some jurisdictions (Wilson-Bates, 2008; Cotton \& Coleman, 2008). The City of Vancouver reported that $31 \%$ of police incidents involved mentally ill persons, with this percentage rising to 
$42 \%$ in the downtown eastside (Wilson-Bates, 2008). Given the marked increase in police interactions with the mentally ill in recent years, it is imperative that police are better trained and educated in how to effectively deal with persons who are mentally ill. Cotton \& Coleman (2008) suggest a substantial increase over the past several years in the level (basic and in-service) of training provided for police officers to ensure their actions are in accordance with "best practices". However, there is no universal model that has been consistently applied in police training.

Of the models that have emerged, the Crisis Intervention Team (CIT) model (premised on the Memphis model) is highly regarded as a "best practice" in the police response to the mentally ill (Griffiths, 2008; Cotton \& Coleman, 2010). One of the greatest strengths of this model is that it involves collaboration between law enforcement and mental health services, thereby providing a specialized response. Developed in 1988, the CIT program provides special training for police to effectively assist them in safely responding to mentally ill persons (Compton et al., 2011). Further, this specialized training allows police to ensure that individuals living with mental illness can obtain the appropriate mental health services in the community (Compton et al., 2011). While the role of police is not the same as a mental health professional such as a psychiatrist, as first responders to incidents involving the mentally ill, it is beneficial and imperative for police officers to have a understanding of, and empathy for, the plight of the mentally ill (U.S. Department of Justice, 1993). For example, it is important for police to recognize the various forms of mental illness and the differences in symptomology which are central to such encounters.

The Vancouver Police Department (VPD) adopted the CIT model as part of a five-year development plan for new constables (Cotton \& Coleman, 2010). Given the use of a systems approach coupled with comprehensive training for officers, this model has the potential to significantly improve police interactions with the mentally ill. Many police departments in the U.S. that have implemented the CIT model have reported many positive benefits and changes including quicker response times, frequent referrals to treatment, and lower arrest rates of mentally ill persons (Hails \& Borum, 2003). Despite these positive developments seen elsewhere, the VPD temporarily implemented the CIT model as a pilot project and with little evaluation research conducted to measure its effectiveness, no longer offers this program to officers. The VPD has recently abandoned its intensive program of training, involving some 32 hours of instruction with respect to police encounters with mentally disordered individuals. There will now be a province-wide program of training (applicable to both the RCMP as well as the various municipal police departments). It will consist of only 8 hours of in-person training and the completion of a 2-hour on-line tutorial. This means that the VPD is no longer committed to the Memphis Model. Interestingly, research indicates that many police officers feel that they are inadequately trained in dealing with the mentally ill and additional training would be useful to avoid potentially volatile encounters (Watson \& Angell, 2007).

\section{Procedural Justice}

As previously mentioned, the need for additional, specialized police training involving the mentally ill is only one facet in improving police encounters. However, understanding the nature of police interactions with mentally ill individuals requires "a well-developed and explicit theoretical understanding of [these] interactions" through the application of a procedural justice framework (Watson \& Angell, 2007, p. 787). This may supplement enhanced training by changing the dynamics of police-citizen encounters in a way that increases the perception of legitimacy in the way mentally disordered people believe they are being treated. 


\section{Procedural Justice Theory}

Tyler's (1990) work on legitimacy provided the basis for the notion of procedural justice. The idea that perceived fairness is essential for ensuring the perceived legitimacy of authoritative decision makers, particularly with respect to marginalized populations, has been applied to many decisionmaking contexts. These include civil commitment, mental-health/drug courts, treatment for mentalhealth patients, the placement of patients in seclusion/restraints and prison discipline, as well as encounters with the police. Legitimacy is incredibly important in these various contexts and perceived procedural justice seems to be an important element in maintaining it. It is not just a matter of ensuring compliance but goes beyond this and involves therapeutic factors that can assist in the recovery process for individuals who have been traumatized by negative experiences with authority figures in the past. In this sense, perceived procedural justice could also be associated with Therapeutic Jurisprudence, which is now a dominant framework for analysis of authoritative decision-making processes.

Procedural justice theory is essentially a theory that involves "procedural fairness for civil dispute resolution" (Solum, 2004, p. 181). The theory is premised on the notion of fairness in the way a person is treated by an authority figure, thereby shaping the process and ultimately the outcome of an encounter (Watson \& Angell, 2007). When applying this perspective to police encounters with mentally ill persons, the way in which an officer treats a person suffering from mental illness is thought to affect whether the encounter results in cooperation or resistance. The legitimacy of state agents is likely determined by the fairness afforded to those with whom they came into contact, notwithstanding race, class, and gender issues. For marginalized people such as the mentally ill, who often have a fear of authority, the way in which they are treated is arguably more important than the outcome of a dispute (Watson \& Angell, 2007). Given the complicated history and relationship between the subjects of such encounters and the police, applying a procedural justice framework can improve the nature of police interactions involving the mentally ill (and other marginalized groups).

Among certain groups in society, interactions with police can be quite intense, often arising from social, cultural, economic and ethnic differences. Consequently, racial minorities and other marginalized groups, such as the mentally ill, can be quite sensitive to prejudicial and disrespectful behaviour from police (Mastrofski et al., 2002). Many social scientists have argued that "disrespectful behavior from the police reduces the citizen's sense of procedural justice and fair play" (Mastrofski et al., 2002, p. 520). Further, coercive tactics used in an effort to gain compliance can potentially backfire and decrease cooperation. That is, individuals who experience inequitable treatment are less likely to assist the state or its agents and are more likely to resist, which contributes to undermining their legitimacy.

When police come into contact with individuals suffering from mental illness, if handled inappropriately, this vulnerable group's perception of police can be seriously damaged. The increase in the number of police interactions with the mentally ill over the last several decades points to the urgency of developing alternative frameworks for shaping these encounters. The application of a procedural justice model in this area can serve as a positive way to change the nature of police encounters. 


\section{Elements of Procedural Justice}

Watson and Angell (2007) have identified three fundamental aspects to the procedural justice model. These include participation, dignity, and trust. Being an active participant in a dispute involves 'having a voice' by allowing one to convey their own perspective and to be heard by the decision maker. Dignity involves the respect and civility one is accorded, and having one's rights acknowledged. Trust involves the extent to which the authority figure is concerned with the welfare of the individual. If these elements are consistently applied by police when dealing with mentally ill persons, they can significantly increase the perceived legitimacy of the police. Watson \& Angell (2007) further argue that, if procedural justice is applied early in an encounter, it is likely to have the greatest impact.

\section{Research}

There have been several studies published on police encounters with the mentally ill that have specifically focused on the attitudes and perceptions of police officers towards the mentally ill (Teplin, 1984b; Hiday, 1999; Cotton, 2004). Often, police officers have preconceived notions about particular groups that they encounter such as the mentally ill. In addition, these encounters between the police and the mentally ill are likely to occur in socially disorganized neighbourhood contexts which can exacerbate the situation. These neighbourhoods tend to attract people who suffer from mental illnesses and who are also likely to be unemployed and poor (Silver, 2000). Police encounters in poor, disenfranchised neighbourhoods usually involve people from a lower socioeconomic stratum, and tend to occur more frequently than police encounters in more affluent neighbourhoods. How the police perceive, and subsequently treat, particular groups are often the result of multiple social and systemic factors. As well, the characteristics of mentally ill persons can also affect how they are perceived by the police.

Conversely, a paucity of research exists regarding the perceptions of people living with mental illness towards police. In their seminal work, the first of its kind from B.C., the study by Brink and his colleagues (2011) examined how people suffering from severe mental illnesses perceive police. The major goal of this study was to "improve the understanding of how people with mental illness perceive and interact with the police", guided by procedural justice theory (Brink et al., 2011, p. 7). Participants in this study were comprised of people suffering from various mental illnesses who had contact with the police. A participatory action group approach was employed as well as different methods for collecting data including interviews $(n=60)$, surveys $(n=244)$, and focus groups $(n=28)$ (Brink et al., 2011).

This study produced interesting results about the nature of police interactions with the mentally ill and attitudes toward the police. The survey results indicated that people living with mental illnesses tend to have more negative views of the police compared to the general population; at the same time, people suffering from mental illness in B.C. are also more likely to come into contact with police compared to the general population (Brink et al., 2011). Overall, three-quarters of survey participants indicated that they held a positive view (attitude) of police regarding the respect and legitimacy of their role; similarly, survey participants generally indicated that they were satisfied with their police encounter, and also satisfied with how the police handled their situations, although there was some degree of variability (Brink et al., 2011).

Underlying the above mentioned findings is the relationship between procedural justice and satisfaction. Participants indicated that the more respect and dignity they received during an 
interaction with police, and the greater the degree to which the process was perceived as procedurally fair, the more likely they were to be satisfied with the process (Brink et al., 2011). While not all participants in this study reported a positive experience, this study provides evidence for consistently applying a procedural justice framework to police encounters with the mentally ill, which is an obvious and essential way of improving future interactions.

The philosophy behind procedural justice theory is quite commonsensical in that one would expect state agents to always employ the elements of this framework when dealing with citizens, to elicit cooperation and compliance, regardless of race, class or gender differences. Given the power differential that exists among police and citizens, increasing the legitimacy of police would benefit the entire community.

\section{Conclusion}

The frequency of interactions between the police and mentally ill individuals has increased in recent years. These encounters have attracted considerable public and media attention, particularly when police encounters with the mentally ill result in serious injury or death. The shift from institutionbased care for persons suffering from mental illness to community care has expanded the role of police in their lives (Cotton, 2004). As police officers have become first responders to incidents involving mentally ill persons, this has created a number of challenges given their inability to effectively deal with these situations. These challenges include concerns over the appropriate use of force with this population, the criminalization of the mentally ill, and the stigmatization and false perceptions police hold towards those individuals living with mental illness (Courey \& McDonald, 2009).

Improving police interactions with mentally ill persons requires adhering to "best practices" in this area. The most widely cited way of improving police encounters with the mentally ill has been increased (specialized) training for police officers (Commission for Public Complaints Against the RCMP, 2010). However, increased police training involves more options for police to manage mentally ill individuals by employing the least restrictive measures, not by using more force. In addition, the use of mobile crisis teams and accessible community-based mental health and social services are also needed. Further, a collaborative approach among the criminal justice and mentally health systems would be very beneficial as police cannot be solely responsible for dealing with this issue.

Applying a procedural justice framework to police interactions with mentally ill persons (and other marginalized groups) has the potential to profoundly change the nature of these police encounters. Despite the simplicity of the theory, it highlights how police or other authorities are perceived by others based on the way in which they are treated. If mentally ill persons perceive that they were treated by the police in a procedurally fair manner with decency and respect, they are more likely to acknowledge the legitimacy of their authority which will likely produce compliance and cooperation. If, however, persons with mental illness experience a police interaction in which they were not treated in accordance with the principles of procedural justice, they are more likely to resist authority. Future research should seek to determine if the presence or absence of perceived procedural justice in an encounter between a police officer and a mentally-disordered person affects the extent to which that person is likely to cooperate with treatment personnel at a later time. Understanding police encounters involving persons suffering from mental illness is enhanced through the application of theory, which provides new ways to identify and implement effective responses. 


\section{Acknowledgements}

The author would like to thank Dr. Simon Verdun-Jones for reviewing an earlier version of this manuscript. This article substantially benefited from his invaluable comments and suggestions.

\section{About the Author}

Farzana Kara is a Master's student at Simon Fraser in the School of Criminology. She can be reached at fbk@sfu.ca.

\section{References}

Abramson, M. (1972). The criminalization of mentally disordered behavior: Possible side effects of a new mental health law. Hospital and Community Psychiatry, 23, 101-105.

Bittner, E. (1967). Police discretion in emergency apprehension of mentally ill persons. Social Problems, 14, 278-292.

Blumberg, M. (1993). Controlling police use of deadly force: Assessing two decades of progress. In R.G Dunham and G.P Alpert (Eds.), Critical Issues in Policing: Contemporary Readings (2nd ed) (pp. 467-492). Prospect Heights: Waveland Press.

Brink, J., Livingston, J., Desmarais, S., Greaves, C., Maxwell, V., Michalak, E., Parent, R., VerdunJones, S., nd Weaver, C. (2011). A Study of How People with Mental Illness Perceive and Interact with the Police. Calgary, Alberta: Mental Health Commission of Canada. Available online at: http://www.mentalhealthcommission.ca

Carman, T. (2012). B.C. police need better training in dealing with mentally ill, survey finds. The Vancouver Sun. Available online at: http://www.vancouversun.com/news/police+need+better+training+dealing+with+mentall $\mathrm{y}+$ survey+finds/6280473/story.html\#ixzz1quhdEelx

Ceyssens, P. (1994). Legal Aspects of Policing. Toronto: Earlscourt Legal Press.

Commission for Public Complaints Against the RCMP. (2008). Legal Analysis of Issues Pertaining to People with Mental Disorders in Contact with the Criminal Justice System: Framework Overview. Available online at: http://www.cpc-cpp.gc.ca/prr/rep/sir/mental-policeeng.aspx

Commission for Public Complaints Against the RCMP. (2010a). Policing Persons with Mental Illness: Issues and Trajectories. Available online at: http://www.cpccpp.gc.ca/prr/rep/sir/mental-traject-eng.aspx 
Commission for Public Complaints Against the RCMP. (2010b). Police Interactions with People Suffering from Mental Health-related Issues. Available online at: http://www.cpccpp.gc.ca/prr/rep/sir/mental-index-eng.aspx

Community Relations Service, U.S. Department of Justice. (1993). Principles of good policing: Avoiding violence between police and citizens." In R.G Dunham and G.P Alpert (Eds.), Critical Issues in Policing: Contemporary Readings (2nd ed) (pp. 182-207). Prospect Heights: Waveland Press.

Cook, J.A., and Wright E.R. (1995). Medical sociology and the study of severe mental illness: Reflections on past accomplishments and directions for future research. Journal of Health and Social Behavior, (Extra Issue): 94-114.

Compton M.T., Broussard B, Munetz M, Oliva J.R., and Watson, A.C. (2011) The Crisis Intervention Team (CIT) Model of Collaboration between Law Enforcement and Mental Health, in Police Practices and Their Impact on Society. New York: Nova Science Publishers, Inc.

Cotton, D. (2004). The attitudes of Canadian police officers toward the mentally ill. International Journal of Law and Psychiatry, 27, 35-146.

Cotton, D., and Coleman, T.G. (2008). A Study of Police Academy Training and Education for New Police Officers Related to Working with People with Mental Illness. Report prepared on behalf of the Police/Mental Health Subcommittee of the Canadian Association of Chiefs of Police and the Mental Health and the Law Advisory Committee of the Mental Health Commission of Canada. Available online at: http://www.mentalhealthcommission.ca/SiteCollectionDocuments/PoliceProject/aa\%20ac ademy\%20report-MHCC_FINAL.pdf

Cotton, D., and Coleman, T.G. (2010). Police Interactions with Persons with a Mental Illness: Police Learning in the Environment of Contemporary Policing. Report prepared for the Mental Health and the Law Advisory Committee and Mental Health Commission of Canada. Available online at: http://www.mentalhealthcommission.ca/SiteCollectionDocuments/PoliceProject/Police\% 20Learning\%20Model_Jul\%2023\%20(4).pdf

Courey, L. and McDonald, D. (2009). Mental Health Issues in Policing. Presentation to the Canadian ssociation of Police Boards.

Criminal Code, R.S.C. 1985, c. C-46.

Goffman, E. (1961). Asylums: Essays on the Social Situation of Mental Patients and Other Inmates. Garden City, N.Y.: Anchor Books. 
Hails, J and Borum, R. (2003). Police training and specialized approaches to respond to people with mental illness. Crime \& Delinquency, 49(1), 52-61.

Hermann, D.H.J. (1986). Barriers to finding effective treatment: A critique of revisions in procedural, substantive, and dispositional criteria in involuntary civil commitment. 39 Vanderbilt Law Review, 39, 83-106. Available online at: http://heinonline.org/HOL/Page?handle=hein.journals/vanlr39\&div=13\&g_sent=1\&colle ction=journals

Hiday, V.A. (1992). Civil commitment and arrests: An investigation of the criminalization thesis. Journal of Nervous and Mental Disease, 180, 141-214.

Hiday, V.A. (1999). Mental illness and the criminal justice system. In A. V. Horowitz and T. L. Scheid (Eds.), A Handbook for the Study of Mental Health: Social Contexts, Theories, and Systems (pp. 508-525). New York: Cambridge University Press.

Hiday, V.A. (2011). Community systems collide and cooperate: Control of deviance by the legal and mental health systems. In B.A. Pescosolido, J.K. Martin, J.D. McLeod, and A. Rogers (Eds.), Handbook of the Sociology of Health, Illness, and Healing: A Blueprint for the $21^{\text {st }}$ Century (pp. 159-170). New York: Springer.

Lamb, H. R., Weinberger, L.E., and DeCuir, W.J. (2002). The police and mental health. Psychiatric Services, 53, 1266-1271.

Lowman, J., Menzies, R.J., and Palys, T.S. (1987). Transcarceration: Essays in the Sociology of Social Control. Aldershot: Gower.

MacAlister, D. (2010). Police-Involved Deaths: The Failure of Self-Investigation. Final Report. Vancouver: B.C. Civil Liberties Association. Available online at: http://beta.images.theglobeandmail.com/archive/00968/B_C_Civil_Libertie_968881a.pd $\mathrm{f}$

Mastrofski, S.D., Reisig, M.D., and McCluskey, J.D. (2002). Police disrespect toward the public: An encounter-based analysis. Criminology, 40, 519-552.

Mental Health Act, R.S.B.C. 1996, c. 288.

Mental Hospitals Act, R.S.B.C. 1948, c. 201.

Menzies, R. J. (1987). Psychiatrists in blue: Police apprehension of mental disorder and dangerousness. Criminology, 25, 429-452.

Police Act - Use of Force Regulation, B.C. Reg. 211/2000. 
Public Health Agency of Canada. (2002). A Report on Mental Illnesses in Canada. Available online at: http://www.phac-aspc.gc.ca/publicat/miic-mmac/chap_1-eng.php

Reuland, M, Schwarzfeld, M, and Draper, L. (2009). Law Enforcement Responses to People with Mental Illnesses: A Guide to Research-Informed Policy and Practice. New York: Council of State Governments Justice Center. Available online at: http://consensusproject.org/downloads/le-research.pdf

Regulations and Procedures Manual (n.d.). Vancouver Police Department. Available online at: http://vancouver.ca/police/assets/pdf/manuals/vpd-manual-regulations-procedures.pdf

Sealy, P. and Whitehead, P.C. (2004). Forty years of deinstitutionalization of psychiatric services in Canada: An empirical assessment. Canadian Journal of Psychiatry, 49, 249-256.

Silver, E. (2000). Race, neighborhood disadvantage, and violence among persons with mental disorders: The importance of contextual measurement. Law and Human Behavior, 24, 449456.

Smyth, M. (2006). Deinstitutionalization deemed a failure. The Province. Available online at: http://www.canada.com/theprovince/news/story.html?id=24b5f60a-825b-48b4-acd8a603e $55 \mathrm{a} 6068$

Solum, L.B. (2004). Procedural justice. Southern California Law Review, 78, 181.

Sunshine, J and Tyler, T.R. (2003). The role of procedural justice and legitimacy in shaping public support for policing. Law and Society Review, 37, 513-548.

Teplin, L.A. (1984a). The criminalization of the mentally ill: Speculation in search of data. In L.A. Teplin (Ed.), Mental Health and Criminal Justice (pp. 63-85). Beverley Hills: Sage Publications.

Teplin, L.A. (1984b). Managing disorder: Police handling of the mentally ill. In L.A. Teplin (Ed.), Mental Health and Criminal Justice (pp. 157-175). Beverley Hills: Sage Publications.

Teplin, L.A. (2000). Keeping the peace: Police discretion and mentally ill persons. National Institute of Justice Journal, 244, 8-15.

Tyler, T.R. (1990). Why people obey the law? New Haven: Yale University Press.

Tyler, T.R., and Huo, Y.J. (2002). Procedural justice and decision acceptance. In T.R Tyler and Y.J. Huo (Eds.), Trust in the Law: Encouraging Public Cooperation with the Police and Courts (pp. 49-58). New York: Russell Sage Foundation.

Verdun-Jones, S and MacAlister, D. (2006). Introduction to Criminal and Civil Law. Toronto: Nelson. 
Watson, A.C., and Angell, B. (2007). Applying procedural justice theory to law enforcement's response to persons with mental illness. Psychiatric Services, 58, 787-793.

Wilson-Bates, F. (2008). Lost in Transition: How a Lack of Capacity in the Mental Health System is Failing Vancouver's Mentally Ill and Draining Police Resources. Report prepared for the Vancouver Police Department. 